\title{
EFFECT OF CORNCOB CELLULOSE NANOPARTICLES ON SILICATE-BASED MUD AT HIGH TEMPERATURE
}

\author{
BAHATI ADNAN HAMAD, MIAO HE, MINGBIAO XU, WEIHONG LIU, \\ JOSEPH X. F. RIBEIRO, JIANJIAN SONG and YIHANG ZHANG \\ Petroleum Engineering College, Yangtze University, 430100 Wuhan Hubei, China \\ \Corresponding author: Miao He, hemiao@yangtzeu.edu.cn
}

Received February 1, 2019

\begin{abstract}
Silicate muds have been successfully used in drilling operations in shale formations. However, the application of silicate muds has shown challenges in controlling their rheological behavior. In this work, a low cost, environmentally friendly and high-performance silicate-based drilling fluid was developed using cellulose nanoparticles (CNPs) extracted from corncob. The study investigates the potential effect of corncob CNPs for improving critical drilling mud properties: rheology and filtration loss at high temperature. The extracted CNPs were characterized by a combination of spectroscopic and chemical techniques, such as FTIR, TEM, SEM and Zeta potential. The concentrations of CNPs were varied from 0.1 to $0.5 \mathrm{wt} \%$ by the weight of the drilling mud at different temperatures from $150{ }^{\circ} \mathrm{C}$ to $170{ }^{\circ} \mathrm{C}$. The experimental results show that CNPs in silicate-based mud substantially improve both filtration and rheological properties. The CNPs not only improved the rheological properties and reduced the filtration loss behavior, but also bolstered the temperature resistance of the drilling mud formulation. In addition, the shear-thinning behavior of the silicate-based drilling mud with CNPs was measured using Bingham-Plastic, and Herschel-Bulkley models. The results show that the Herschel-Bulkley model adequately describes the shear-thinning relationship between the shear stress and shear-strain rate of the CNP silicate-based mud.
\end{abstract}

Keywords: silicate-based mud, corncob cellulose nanoparticles, rheology, filtration, rheological models

\section{INTRODUCTION}

The success of drilling a well critically depends on the proper choice of the drilling mud to be used. ${ }^{1}$ The drilling fluid is an important part of the drilling operation and its properties affect the efficiency of the drilling process. The drilling fluid (DF) is intended to remove and suspend cuttings from the wellbore to the surface, respectively, control formation pressure, minimize formation damage, cool and lubricate drill bits. ${ }^{2}$ Drilling fluids (DFs) can be categorized as water-based mud (WBM), oil-based muds $(\mathrm{OBM})$, and foam. ${ }^{3}$ Silicate-based mud is a waterbased mud that has been used in the oil industry for many years. The silicate-based mud was developed to drill water-sensitive reactive shales, dispersible chalk, and illite clays. The inhibition provided by the silicate system is importantly greater than that of other water-based systems, approaching the level of an oil-based system. ${ }^{4}$ In addition, the benefits associated with the use of silicate drilling fluid include stable wellbore, good hole cleaning, casing elimination, prevention of low gravity solids build-up, among other features. ${ }^{5}$ Potassium silicate drilling fluids provide good shale inhibition and wellbore stability in reactive shales, they can be reused in multi-well drilling programs and are easy to dispose of, with low associated costs. ${ }^{6}$ Despite their benefits, controlling mud properties may be difficult when proper polymer additives are not available for maintaining rheology and fluid loss control. $^{7}$

The rheological and fluid loss profiles of silicate-based muds are very similar to those of the water-based muds (WBMs). ${ }^{8}$ Most of the WBMs use bentonite clay, which has good rheological behavior and shear-thinning viscosity. This bentonite begins breaking down chemically at a high temperature of $120{ }^{\circ} \mathrm{C},{ }^{9}$ which increases the fluid loss in the formation, and as a result, makes the fluid ineffective for a high-temperature drilling environment.

Nanoparticles (NPs) have been found to be valuable additives and turned out to be promising 
in many oilfield applications in the upstream oil and gas industry. ${ }^{10}$ It has been demonstrated by various studies over the last years that different NPs can be used to enhance the performance of drilling fluids in terms of their rheological and filtration characteristics. ${ }^{11-13}$ NPs are now commercially available at reasonable prices and are appropriate to use as drilling fluid additives due to their superior properties, stemming from their extremely high surface-to-volume ratios. Thus, made-to-order smart drilling fluid with specific requisite properties could be developed to meet the expected requirement in demanding downhole at HTHP. ${ }^{14}$

Despite the beneficial applications of NPs, most of the synthesized NPs used are inorganic materials, which are insoluble, non-biodegradable, and somewhat detrimental to the health of drilling operators. Inorganic NPs, such as $\mathrm{FeO}_{3}, \mathrm{Fe}$ and Ca-based NPs, as well as nano-silica, can pass through the tissue of living organisms. ${ }^{15}$ Different natural polymers (e.g., starch, ${ }^{16}$ guar gum, ${ }^{17}$ xanthan gum, ${ }^{18}$ cellulose derivatives, ${ }^{19}$ as well as synthetic polymers (e.g., polyacrylamide ${ }^{20}$ and polyacrylates ${ }^{21}$ ), and inorganic nanoparticles (e.g., graphene, ${ }^{22}$ nano-silica, ${ }^{23}$ carbon nanotubes, ${ }^{23}$ and metal oxides ${ }^{2}$ ) have been used as additives in DFs. All these have been applied to improve the rheological and filtration performance of DFs.

Cellulose nanoparticles (CNPs) have drawn increased attention in the nanotechnological field due to their biodegradability, renewable nature, low-cost production, high aspect ratios, high surface area, high strength, and high crystalline structures. $^{24}$ Thermal stability plays a very important role in restricting the properties and the application scope of polymer and CNP composites. The thermal stability of CNPs is influenced by their physical and chemical structure. $^{25}$ The higher crystallinity of the cellulose obtained after the removal of hemicellulose and lignin components is related to the higher thermal stability of fibers.

The effect of adding NPs on the rheological and filtration properties of water-based drilling fluids has been studied by different researchers. ${ }^{21,26-28}$ The results showed that the addition of a low concentration of NPs significantly improved filtration and rheological properties. In addition, the formation of a thin and impermeable filter cake and its effectiveness depend on the NP concentration. However, most of the studies on the rheology of water bentonite dispersions have been performed at room temperature. ${ }^{9}$ Few of the studies focusing on this application of nanoparticles used them at high temperature. ${ }^{13,26,29-31}$ Moreover, there are very few, if any, detailed studies on the effect of CNPs on the rheology and filtration in silicate-based mud at high temperature.

This work has been carried out to extract cellulose nanoparticles from corncorb and analyze their potential to be used as an environmentally friendly drilling fluid additive. Thus, the rheological and filtration loss properties of the extracted CNPs at high temperature were investigated. Besides, the shear stress/shear strain rate relationship of silicate-based drilling mud was studied using non-linear models.

\section{EXPERIMENTAL}

\section{Extraction of CNPs from corncob}

Corncobs were purchased from retailers in Wuhan city, Hubei, China. They were washed thoroughly with distilled water and dried in an oven at $90{ }^{\circ} \mathrm{C}$ for 24 hours; then ground and sieved. The ground corncobs were treated with a sodium hydroxide solution (5 wt\% $\mathrm{NaOH}$ ), at a ratio of 1:20 (corncob:alkali). The mixture was stirred at $80{ }^{\circ} \mathrm{C}$ for 2 hours, cooled and then filtered. The residue was bleached using $1.7 \mathrm{wt} \%$ sodium hypochlorite solution $(\mathrm{NaOCl})$ at $80{ }^{\circ} \mathrm{C}$ for 2 hours. Finally, acid hydrolysis was performed by stirring the bleached residues in sulfuric acid (64 wt\%) for 45 to 60 minutes at $45{ }^{\circ} \mathrm{C}$; the mixture was then centrifuged at $10,000 \mathrm{rpm}$ for 10 minutes to remove the acid solution. The extraction procedure of CNPs is presented in Figure 1.

\section{Characterization of CNPs}

The morphology, chemical structure and dispersion of CNPs were investigated by using scanning electron microscopy (SEM Model SU 8010, HITACHI, Japan), Fourier Transform Infrared Spectroscopy (FTIR Model Bruker Tensor 27), High-Resolution Transmission Electron Microscopy (TEM Model JEM-2100F), and Zeta potential analysis (Meter Model JS94, Shanghai Powereach Digital Technology Equipment Co., Ltd.).

\section{Preparation of CNP-drilling mud}

With the aid of a Hamilton Beach mixer (Model GJ-1), the formulation of the CNP-drilling mud was designed to achieve a mud weight of $1.2 \mathrm{~g} / \mathrm{cm}^{3}$. The CNP-drilling mud was prepared using the required amount of CNPs. They were added in concentrations of $0.1,0.3$ and $0.5 \mathrm{wt} \%$ to deionized water in separate cups and mixed for 30 minutes through vigorous mechanical stirring at a speed of $11,000 \mathrm{rpm}$. Then, 3 wt\% of bentonite (BT) powder was added slowly into the CNP suspensions and stirred at a speed of 10,000 rpm for 30 minutes. After mixing the bentonite with CNPs, other additives, such as potassium silicate (3 
wt $\% \quad \mathrm{~K}_{2} \mathrm{SiO}_{3}$ ), sodium hydroxide (1 wt $\% \mathrm{NaOH}$ ), polyanionic cellulose (0.3 wt $\%$ PAC), potassium humate $(3 \mathrm{wt} \%)$ and barite, were added sequentially to the mixture while mixing.
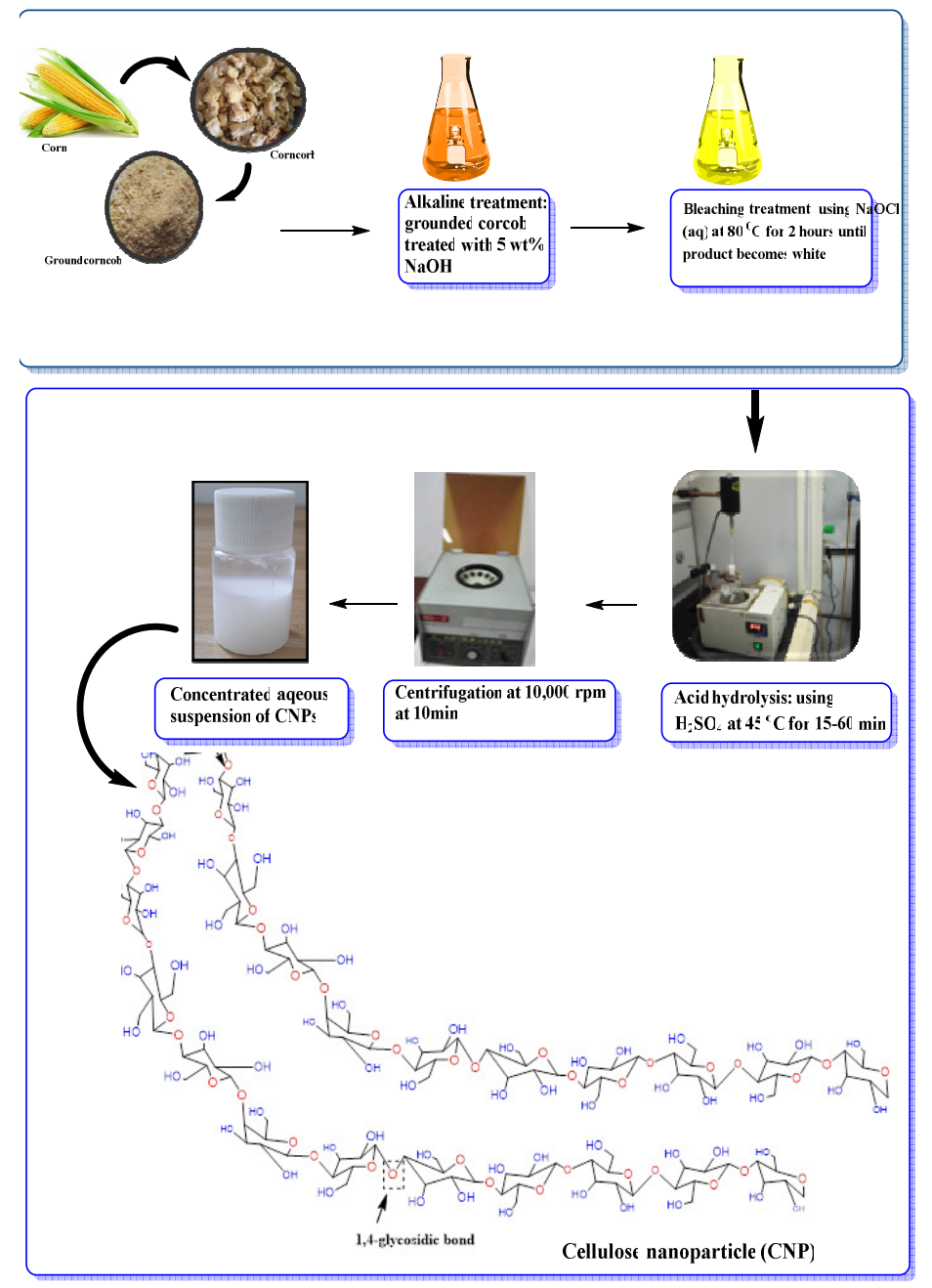

Figure 1: Extraction of cellulose nanoparticles (CNPs)

\section{Rheological and fluid loss measurement}

The influence of the CNP additive on the rheological behavior was investigated at a temperature from 150 to $170{ }^{\circ} \mathrm{C}$, using a viscometer (Model 1103, Qingdao Chuang Meng Instrument Co., Ltd., China). The steady-flow shear viscosity for each sample was measured at shear rates of $1022,511,341,170,10$, and $5 \mathrm{~s}^{-1}$, at a fixed speed of $600,300,200,100,6$, and 3 $\mathrm{rpm}$, respectively, and at a temperature of $60{ }^{\circ} \mathrm{C}$. The rheological properties, such as yield stress (YP), plastic viscosity (PV), and apparent viscosity (AV), of the drilling mud were calculated according to the following equations:

$$
\begin{array}{ll}
A V=\theta_{600} / 2 & (\mathrm{mPa} . \mathrm{s}) \\
P V=\theta_{600}-\theta_{300} & (\mathrm{mPa} . \mathrm{s}) \\
Y P=A V-P V & (\mathrm{~Pa})
\end{array}
$$

where $\theta_{600}$ and $\theta_{300}$ are dial readings at 600 and 300 rpm, respectively.

Gel strength (10 seconds/10 min): the values for gel strength were read at 10 seconds and 10 minutes on the viscometer, at a speed of $3 \mathrm{rpm}$. The drilling fluids must remain static prior to each test, and the highest peak reading should be taken. The thixotropic behavior of the drilling fluid consists in its strength to suspend cuttings under static conditions.

Filtration measurements were performed at room temperature based on API standards. ${ }^{32}$ The tests were conducted using API filter press equipment (Model GGS42, Qingdao Chuang Meng Instrument Co., Ltd., China) with filter paper for $45 \mu \mathrm{m}$ particle size retention. The filtrate volumes were collected in a measuring cylinder after 30 minutes. Then, the thickness of each filter cake was measured and recorded in millimeters $(\mathrm{mm})$. The fluid losses from 5 
to 25 minutes were calculated by using the following formula: ${ }^{33}$

$$
f_{1}=f \times \sqrt{T}_{1} / \sqrt{T}
$$

where $\mathrm{f}$ is the known filtrate at a time interval of $\mathrm{T}$, and $\mathrm{f}_{1}$ is the unknown filtrate at a time interval of $T_{1}$.

\section{Rheological modeling}

Many models have been used to describe the shear stress versus shear-strain rate behavior of drilling muds. In this paper, the Bingham plastic and HerschelBulkley models were used to study the shear-thinning behavior of the silicate-based mud. The Bingham plastic model includes both yield stress and limiting viscosity at a finite shear rate: ${ }^{34}$

$$
\tau=\tau_{0}+\mu_{p} \times \dot{\gamma}
$$

where $\tau$ is the shear stress, $\tau_{0}$ is the yield point or yield stress, $\mu_{p}$ is the plastic viscosity, and $\dot{\gamma}$ is the shear rate. This model has been found to be inadequate because shear stress/shear rate is no longer linear and it overestimates the fluid yield stress (yield point).

The Herschel-Bulkley model is a combination of the Bingham plastic model and the power model, and can be represented mathematically as follows: ${ }^{35,36}$

$\tau=\tau_{0}+k \times \dot{\gamma}^{n}$

where $k$ is the flow consistency coefficient and $n$ is the flow behavior index.

\section{RESULTS AND DISCUSSION \\ Characterization of CNPs}

The FTIR spectrum of the CNPs is shown in Figure 2. The absorption bands around 3439, 2919,1652 , and $1056 \mathrm{~cm}^{-1}$ were attributed to the $\mathrm{O}-\mathrm{H}, \mathrm{C}-\mathrm{H}$ stretching, $\mathrm{C}-\mathrm{C}$ bending, and $\mathrm{C}-\mathrm{O}$ stretching vibrations on cellulose, respectively. The absence of absorption bands around 1700-
$1750 \mathrm{~cm}^{-1}$ and 1510-1520 $\mathrm{cm}^{-1}$, which are characteristics of carbonyl and ester groups found in lignin or hemicellulose ${ }^{37}$ allowed inferring the successful separation of cellulose. Both of them disappeared after bleaching and acid hydrolysis.

Figure 3 shows SEM and TEM images of the CNPs at different magnifications. As clearly seen from the SEM images, the CNPs agglomerated into entangled rod-like and rough waving structures, which is beneficial for a viscosifying effect. Besides, the TEM images show that the sample comprised a great number of interconnected micropores, as well as a few macropores.

The zeta potential is the potential difference across the ionic layer around a charged colloid ion. Generally, when all the particles have a large positive or negative Zeta potential (where the positivity and negativity are greater or lower than $+30 \mathrm{mV}$ and $-30 \mathrm{mV}$ ), they will repel each other and the dispersion is stable. Besides, when the particles have low $\zeta$ values, there will be an insufficient force to prevent the particles from aggregating. ${ }^{38}$

Figure 4 shows the relationship between the zeta potential and the $\mathrm{pH}$ of the CNPs. It can be observed that all the samples have no point of zero charge; they exhibit negative zeta potential within the $\mathrm{pH}$ range from 3 to 8 . The $\zeta$ potential was significantly influenced by the $\mathrm{pH}$ of the CNP dispersions. The $\zeta$ value of the cellulose nanoparticles ranged from -32 to $-46 \mathrm{mV}$, in the range of $\mathrm{pH}$ from 3 to 8 . These results show the good stability of the cellulose nanoparticles under different $\mathrm{pH}$ values.

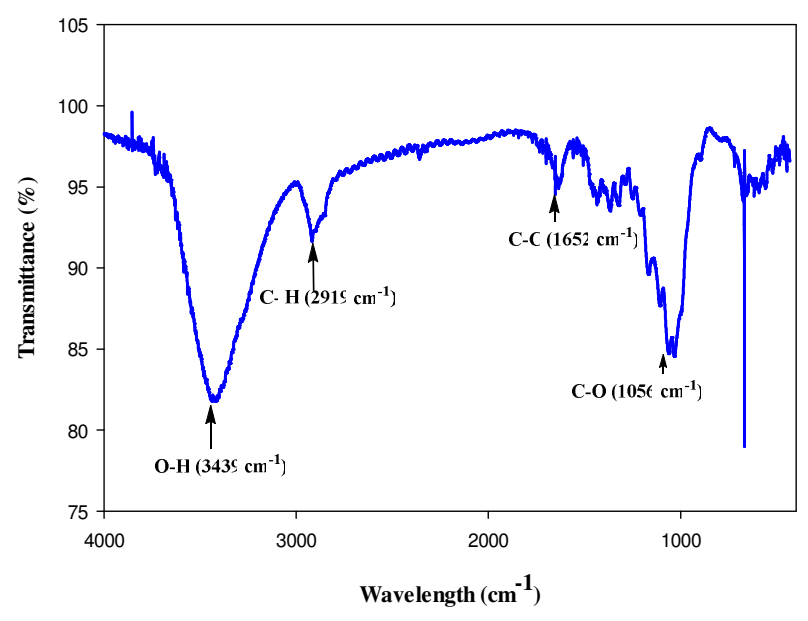

Figure 2: FTIR spectrum of CNPs 


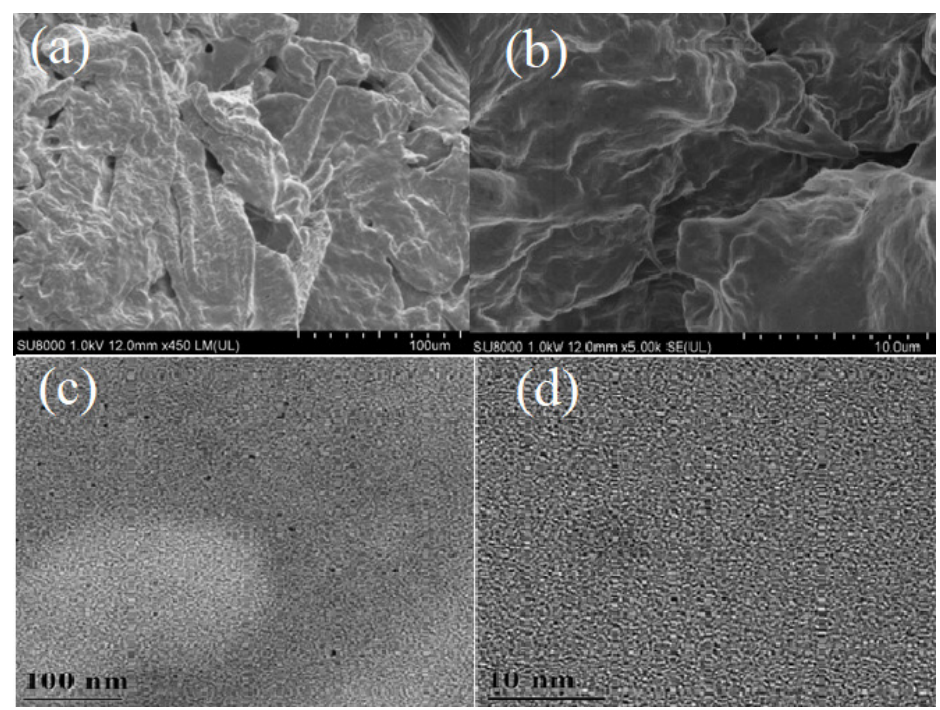

Figure 3: SEM micrographs (a and b) and TEM images (c and d) of CNPs

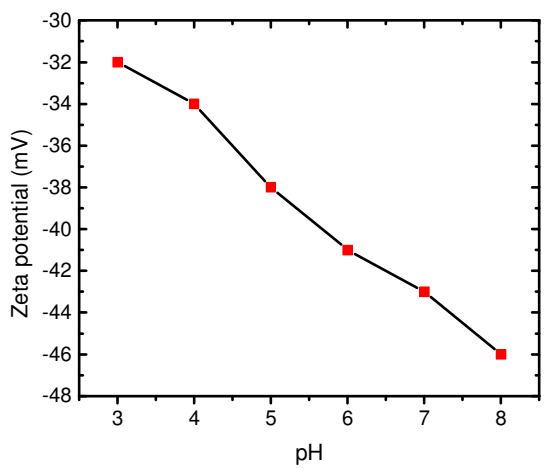

Figure 4: Zeta potential of CNPs as a function of $\mathrm{pH}$

\section{Rheological properties}

Drilling fluids with good pumpability display lower viscosity at high shear rate and higher viscosity at lower shear rate. The high viscosity of the fluids at low rates is required to suspend drilled cuttings and transport them out of the wellbore. Meanwhile, the low viscosity of drilling fluids at high shear rates allows the fluids to flow downhole with less resistance.

\section{Viscosity versus shear-strain rate}

Figure 5a shows the variation of viscosity as a function of shear rate for the base fluid and CNP/PAC/BT-drilling mud. The addition of CNPs effectively increased the viscosity of the silicate-based mud and led to shear thinning behavior, which is more desirable for the drilling fluid application. The CNPs enhanced the surface interaction among PAC, BT and the silicate molecules. It was found that the drilling muds with CNPs generate higher viscosities than those of the base fluid (Fig. 5). Moreover, it was observed that higher concentration of CNPs $(0.5$ wt $\%$ ) resulted in increased viscosity along the whole shear thinning curve. Both mud samples (CNP/PAC/BT and base fluids) had high viscosities at low shear rate $\left(5 \mathrm{~s}^{-1}\right)$, but the viscosity decreased as the shear rate increased. This occurred due to the microstructural transition from a state dominated by thermal Brownian motion, occurring normally at low shear rates, to a state where the hydrodynamic forces balance the thermal forces at high shear rates. ${ }^{39}$ If attractive forces occur, collisions between particles lead to the formation of agglomerates. In addition, at low shear rates, the liquid within the agglomerate structures is immobilized and hence lead to high viscosity. At higher shear rates, the flocs and 


\section{BAHATI ADNAN HAMAD et al.}

agglomerates break up, releasing the trapped liquid, thus reducing viscosity. ${ }^{40,41}$

By contrast, the CNP/PAC/BT-silicate mud had higher viscosity than the base fluid because the CNPs are hydrophilic, as they comprise a large number of a hydroxyl groups $\left(\mathrm{OH}^{-}\right)$on their surface, which facilitate intra- and intermolecular hydrogen bonding between CNPs and other components (BT and PAC) in the fluids. The CNPs immediately attach to the edge of the BT layers via the formation of hydrogen bonds (Fig. 6) between their hydroxyl groups, and the ionic bond between the positively charged edge site of BT layers and the negatively charged sulfate groups of CNPs. Due to their high surface area and numerous hydroxyl groups on the surface, CNPs

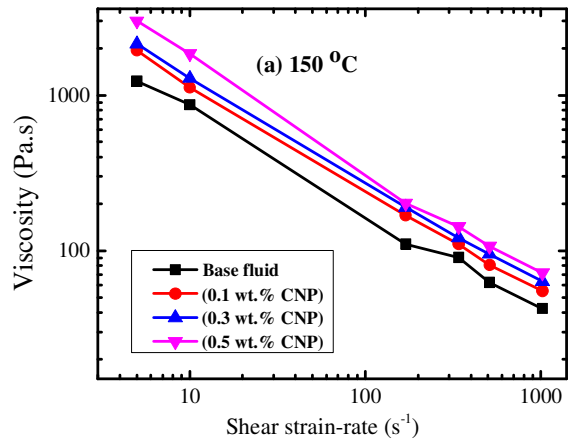

have a strong gel formation capacity. Many water molecules are bound at the vicinity of CNPs via hydrogen bonding. ${ }^{42}$ Therefore, a stronger hydrogen-bonding network formed in the fluids with added CNPs, generating a rigid network among the BT layers, CNPs and immobilized water molecules, which develop a strong resistance to flow under shear force, leading to a significant improvement in the rheological properties. Based on the above observations, it can be concluded that the CNP/PAC/BT-silicate mud exhibits good rheological properties, compared to the base fluid. This is due to the formation of a particular interaction between the CNPs, BT, PAC and the silicate layer.

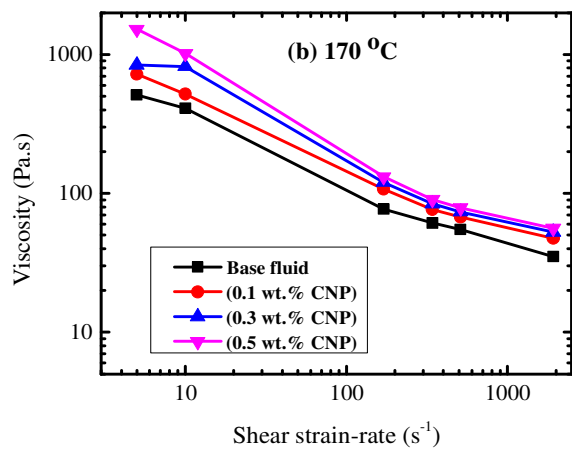

Figure 5: Viscosity versus shear-strain rate of drilling muds

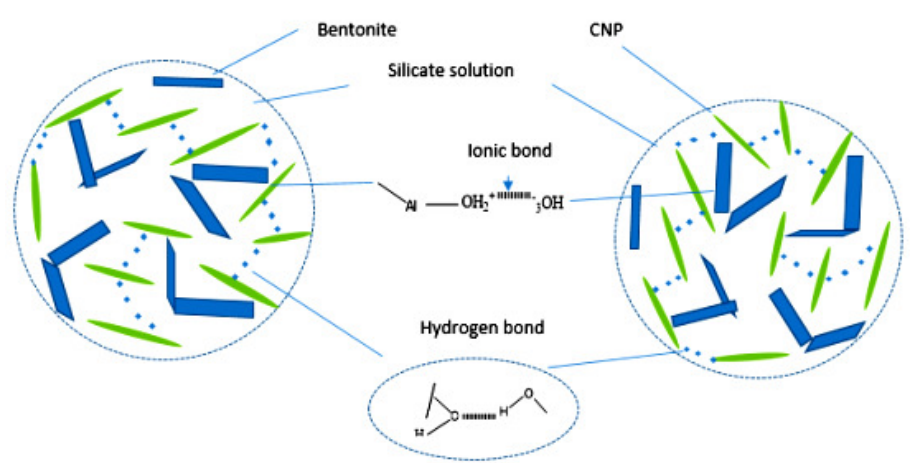

Figure 6: Schematic diagram of the formation of an ionic and hydrogen bond between CNPs and bentonite in silicate-based drilling mud

It was observed that the viscosity of the silicate mud was comparatively higher than that of the water-based mud. This observation was compared with the findings of other studies on water-based muds. ${ }^{26}$ The viscosity is greater when using potassium silicate than when water is used, because when bentonite is mixed with the potassium silicate solution, its viscosity increases based on the mechanism of adsorption of $\mathrm{H}_{2} \mathrm{O}$ and $\mathrm{OH}^{-}$. Bentonite has a very strong base exchange property in an electrolyte, such as potassium silicate, compared with other minerals, such as 
kaolinite. $\mathrm{Ca}^{2+}$ ions existing in the bentonite particles are substituted by $\mathrm{K}^{+}$ions in the potassium silicate through absorbing $\mathrm{OH}^{-}$ions (Eq. 1). This indicates that the stronger the water absorption property of the bentonite particles, the greater the amount of $\mathrm{OH}^{-}$and $\mathrm{H}_{2} \mathrm{O}$ taken from the potassium silicate. This shows that the hardening reaction depends upon the hydrolysis of the potassium silicate, and the high absorption value of bentonite speeds up the hydrolysis of the potassium silicate. $^{43}$

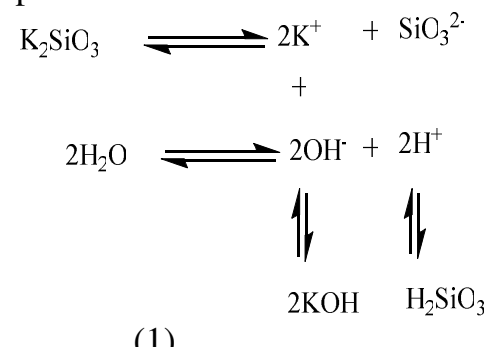

(1)

\section{Shear stress versus shear-strain rate}

The rheograms (shear stress versus shear rate) of the drilling fluid formulations are shown in Figure 7. The results reveal that the addition of CNPs considerably increased the shear stress at all the temperatures. The increments were found to be more pronounced with an increase in the concentration of CNPs. As the concentration of CNPs increased from 0.1 to $0.5 \mathrm{wt} \%$, the shear stress also increased. For example, at the highest shear rate of $1022 \mathrm{~s}^{-1}$, the CNP/PAC/BT-drilling mud with 0.1, 0.3 and $0.5 \mathrm{wt} \%$ CNPs had a shear rate of 55.2, 63.4 and $72.1 \mathrm{~Pa}$, respectively. The observed phenomenon is ascribed to an improved molecular interaction between the CNPs and the base fluid, as explained previously. The molecular interaction significantly increased with an increase in CNPs concentration.

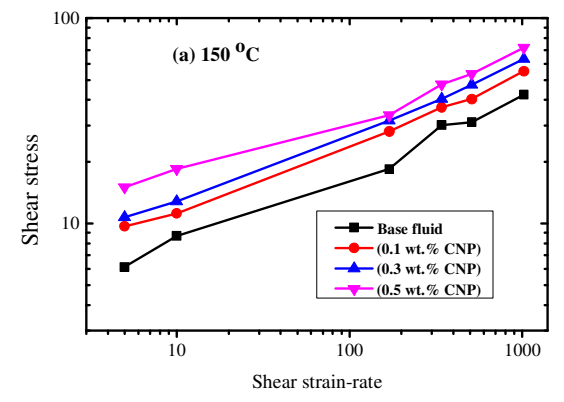

Figure 7: Shear stress versus shear-strain rate of drilling muds at different temperatures
Effect of temperature on plastic viscosity and yield stress

Temperature is an important factor that determines the stability of the drilling mud. Figure 8 shows the effect of two temperature values, i.e. $150{ }^{\circ} \mathrm{C}$ and $170{ }^{\circ} \mathrm{C}$, on $\mathrm{YP}$ and $\mathrm{PV}$ of the $\mathrm{CNP} / \mathrm{PAC} / \mathrm{BT}$ and the base fluid. Figure 8 shows an increase in temperature significantly reduces the PV of the two drilling fluids to low values. This observation was also reported earlier. ${ }^{44}$ Furthermore, we observed that the PV of the base fluid decreased from 22.48 to $13.28 \mathrm{cP}$, as the temperature was increased from 150 to 170 ${ }^{\circ} \mathrm{C}$, respectively. Similarly, the PV of the CNP/PAC/BT-drilling mud (0.5 wt $\%)$ decreased from 37.2 to $33.8 \mathrm{cP}$, as the temperature was increased from $150{ }^{\circ} \mathrm{C}$ to $170{ }^{\circ} \mathrm{C}$, respectively. Likewise, Figure $8 \mathrm{~b}$ reveals that the YP of the base fluid and the CNP-drilling mud decreased when the temperature increased. The YP of the base fluid dropped from 37.82 to $27.6 \mathrm{lb} / 100 \mathrm{ft}^{2}$ as the temperature was increased from $150{ }^{\circ} \mathrm{C}$ to $170{ }^{\circ} \mathrm{C}$. Similarly, the YP of the CNP-drilling mud decreased from 69.8 to $44.8 \mathrm{lb} / 100 \mathrm{ft}^{2}$ when the temperature was increased from 150 to $170{ }^{\circ} \mathrm{C}$ The results showed that, without addition of CNPs, the plastic viscosity and yield stress of the PAC/BT-silicate mud was quite unstable with temperature changes.

\section{Gel strength}

Gel strength is defined as shear stress measured at low shear rate after mud circulation is stopped for a period and then is resumed. Table 1 shows the gel strength as a function of time for both CNP/PAC/BT and the base fluid, at the temperatures of $150{ }^{\circ} \mathrm{C}$ and $170{ }^{\circ} \mathrm{C}$.

The results indicate that the addition of CNPs increased the gel strength characteristics of the CNP/PAC/BT-drilling mud, compared to that of the base fluid.

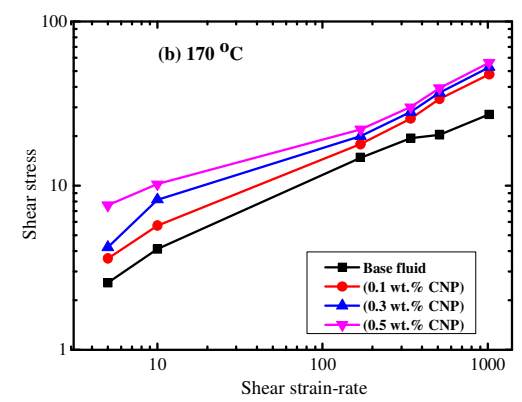

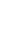




\section{BAHATI ADNAN HAMAD et al.}
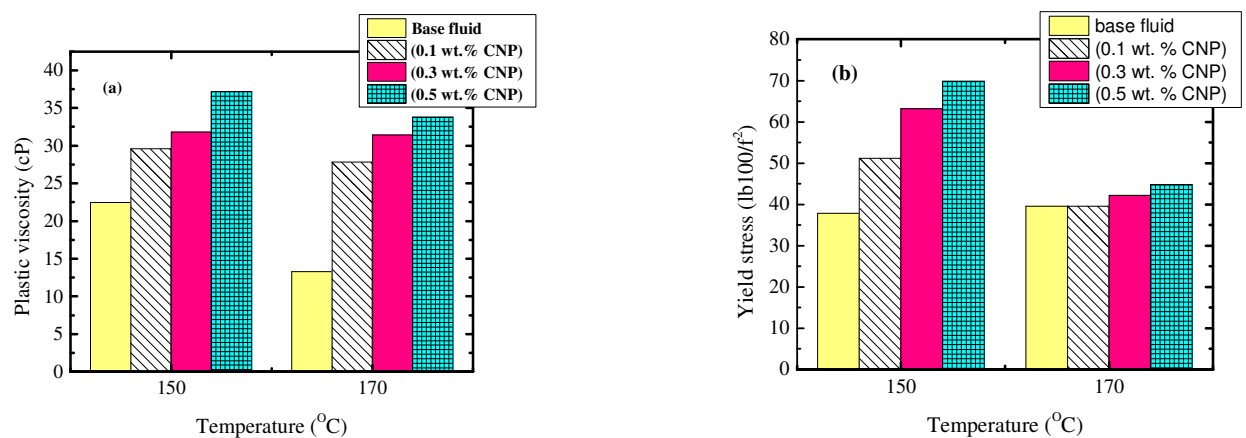

Figure 8: Effect of temperature on plastic viscosity and yield stress of drilling muds: (a) plastic viscosity and (b) yield stress

Table 1

$\mathrm{Gel}_{10 \mathrm{~s}}$ and $\mathrm{Gel}_{10 \mathrm{~min}}$ strength as a function of the concentration of CNPs

\begin{tabular}{ccccc}
\hline \multirow{2}{*}{ Concentration } & \multicolumn{2}{c}{$150{ }^{\circ} \mathrm{C}$} & \multicolumn{2}{c}{$170{ }^{\circ} \mathrm{C}$} \\
\cline { 2 - 5 } & $\mathrm{Gel}_{10 \mathrm{~s}}$ & $\mathrm{Gel}_{10 \min }$ & $\mathrm{Gel}_{10 \mathrm{~s}}$ & $\mathrm{Gel}_{10 \min }$ \\
\hline 0.0 & 12.0 & 19.2 & 5.0 & 9.2 \\
0.1 & 18.9 & 36.1 & 7.6 & 15.8 \\
0.3 & 20.4 & 41.0 & 8.1 & 16.4 \\
0.5 & 31.2 & 52.1 & 15.3 & 28.5 \\
\hline
\end{tabular}

The increase of gel strength reveals the ability of CNPs to improve the gel strength properties of the silicate-based mud. This will prevent problems, such as mechanical pipe sticking and hole pack-off, by developing and maintaining an adequate gel profile in the event of cessation of drilling operations. ${ }^{45}$

\section{Constitutive rheological models}

The results of the rheological studies conducted on the CNP/PAC/BT-drilling mud, using different concentrations of CNPs and at different temperatures $\left(150{ }^{\circ} \mathrm{C}\right.$ to $\left.170{ }^{\circ} \mathrm{C}\right)$, were fitted to the Bingham plastic and HerschelBulkley models. Table 2 shows the rheogram (shear stress vs shear rate) of the CNP/PAC/BTdrilling mud at different temperatures and concentrations. It was observed that the HerschelBulkley model fitted better the experimental data, when compared to the Bingham plastic model. The Herschel-Bulkley model performs satisfactorily, with $95 \%$ confidence, in describing the rheological behavior of all the mixtures at various concentrations of CNPs and different temperatures, due to a high value of $\mathrm{R}^{2}$ (close to 1). It was observed that a yield stress must be applied to the fluid to initiate flow, which was found by extrapolating the shear stress versus shear rate curve to zero-shear conditions. ${ }^{30}$ An improvement of the rheological properties at high temperature was achieved when adding CNPs to the base fluid.

The calculated values of the flow index $(n)$, consistency index $(k)$ and shear stress $\left(\tau_{\mathbb{g}}\right)$ of the muds are listed in Table 2 . We observed an increase in the yield stress with higher temperature and concentration of CNPs. Besides, there is a decrease in the flow consistency index and an increase in the flow behavior index with increasing temperature. The exponent $n$ represents shear thinning behavior of the drilling mud when $n<1$ and shear thickening behavior when $n>1.35,46$

Table 2 shows that $n<1$ for each DF at various concentrations of CNPs, thus indicating shear thinning behavior. Furthermore, we clearly observe that a higher yield stress is achieved by the addition of $0.5 \mathrm{wt} \%$ CNPs. This is because yield stress is required to initiate fluid flow as the concentration of CNPs is increased in the system. Thus, in a drilling operation, a fluid with a high yield stress is desirable as it has better drill cutting carrying capacity. The limitation of the Bingham plastic model is the absence of the flow behavior index $n$, which can result in inaccurate data fitting. Therefore, in this study, we used the yield stress of Herschel-Bulkley's model to demonstrate that the CNP/PAC/BT-drilling mud can be considered as an appropriate candidate for being used as a drilling fluid. 
Cellulose

Table 2

Calculated parameters for CNP/PAC/BT at different CNP concentrations and temperature using Bingham plastic (BP) and Herschel-Bulkley (HB) models

\begin{tabular}{|c|c|c|c|c|c|c|c|c|c|c|}
\hline \multirow{2}{*}{$\begin{array}{l}\text { Temperature } \\
\left({ }^{\circ} \mathrm{C}\right)\end{array}$} & \multirow{2}{*}{$\begin{array}{l}\text { CNP concentration } \\
(\mathrm{wt} \%)\end{array}$} & \multicolumn{3}{|c|}{ Bingham plastic model } & \multirow[b]{2}{*}{$\Sigma Q^{2}$} & \multicolumn{5}{|c|}{ Herschel-Bulkley model } \\
\hline & & $\tau_{0}$ & $\mu_{p}$ & $\boldsymbol{R}^{2}$ & & $\boldsymbol{T}_{0}$ & $\boldsymbol{k}$ & $n$ & $\boldsymbol{R}^{2}$ & $\Sigma Q^{2}$ \\
\hline \multirow{4}{*}{150} & 0.0 & 10.93 & 0.0347 & 0.890 & 5.260 & 2.883 & 1.777 & 0.4485 & 0.985 & 2.275 \\
\hline & 0.1 & 15.34 & 0.0434 & 0.899 & 6.266 & 4.456 & 2.595 & 0.4279 & 0.998 & 1.037 \\
\hline & 0.3 & 17.1 & 0.0505 & 0.909 & 6.888 & 5.604 & 2.525 & 0.4514 & 0.999 & 0.371 \\
\hline & 0.5 & 21.32 & 0.0547 & 0.930 & 6.458 & 12.21 & 1.529 & 0.5298 & 0.997 & 1.679 \\
\hline \multirow{4}{*}{170} & 0.0 & 6.041 & 0.0321 & 0.915 & 4.215 & 0.319 & 1.005 & 0.5141 & 0.989 & 1.684 \\
\hline & 0.1 & 7.544 & 0.0429 & 0.945 & 4.443 & 1.551 & 0.8745 & 0.5729 & 0.999 & 0.745 \\
\hline & 0.3 & 9.198 & 0.0461 & 0.953 & 4.410 & 3.617 & 0.7327 & 0.6072 & 0.996 & 1.404 \\
\hline & 0.5 & 11.47 & 0.0469 & 0.965 & 3.826 & 6.867 & 0.5238 & 0.6565 & 0.998 & 1.054 \\
\hline
\end{tabular}




\section{Filtration property}

The filtration rate is often the most important property of a drilling fluid, particularly when drilling permeable formations where the hydrostatic pressure exceeds the formation pressure. Proper control of filtration can prevent or minimize wall sticking and drag, and in some areas improve borehole stability. ${ }^{47}$ A suitable drilling mud has desirable filtration properties, i.e. low filtrate volume and a thin filter cake.

For all the mud samples, the received filtrate was light brown and had very low viscosity, compared to the mud, showing that the main component in the filtrate was water. Initially, the frequency of filtrate drops was high. After 7 minutes, however, reduced frequency was observed as the time increased. Figure 9 shows the fluid loss volume as a function of time for $\mathrm{CNP} / \mathrm{PAC} / \mathrm{BT}$ and the base fluid. The addition of CNPs to the silicate-based mud results in a significant reduction of the filtrate volume, compared to that of the base fluid. This reduction in the filtrate volume is due to the fact that CNPs can withstand higher temperatures without losing their superior properties, thus leading to superior filtration control.

The results show that, in all the mud samples, the fluid loss volume gradually decreased as the concentration of CNCs increased from 0.1 to 0.5 wt $\%$, as also reported earlier. ${ }^{48}$ Increased fluid viscosity decelerates the filtration rate. ${ }^{49,50}$ At a temperature of $150{ }^{\circ} \mathrm{C}$, the filtrate volumes were low in all the muds (Fig. 9a and 9b), ranging from $1.59 \mathrm{~mL}$ to $9.3 \mathrm{~mL}$. When the temperature increased to $170{ }^{\circ} \mathrm{C}$, the filtrate volume, particularly that of the base fluid, increased from $13.14 \mathrm{~mL}$ to $32.2 \mathrm{~mL}$. An increase in temperature will usually result in an increase in the filtration rate because of adverse temperature effects on filtration control agents and decreased fluid phase viscosity. The higher filtration volume of the base fluid can be attributed to the fact that bentonite forms a weaker structure under high temperatures, leading to a less compacted and more permeable filter cake that allows more fluid to escape from the filter medium. In addition, a higher temperature may also increase the solubility of contaminants and, therefore, decrease the effectiveness of filtrate loss control chemicals. This observation was also reported previously. ${ }^{51}$ Moreover, the colloidal fraction flocculates and increases filtration at elevated temperature. ${ }^{33}$ When the CNPs were added to the silicate mud, filtrate volume reduced compared to that of the base fluid, although at the same temperature. The reduction of fluid loss with increasing concentration of CNPs was explained by the high affinity of cellulose to water and its ability to absorb and hold water. ${ }^{52}$ As the cellulose size is reduced to the nanoscale, all the CNPs have an increased surface area to volume ratio, increasing the contact area between cellulose and water, thus improving the fluid loss control ability. In addition, CNPs comprise many hydroxyl groups $\left(\mathrm{OH}^{-}\right)$, these $\mathrm{OH}^{-}$groups form strong hydrogen bonding with water molecules and keep them bound on the fibril surface, which enables CNPs to hold more water and results in reduced filtration loss.

Filter cake is built up when the insoluble solid part of the fluid slurry becomes deposited on a permeable material as the slurry contacts that material under pressure. With fluid losses, thick filter cakes and excessive filtration increase the possibility of tight hole occurrence while drilling, because of the increased torque and drag on the drill string. This increases the likelihood of stuck pipes, lost circulation, poor quality well log data, and formation damage. ${ }^{2,47}$

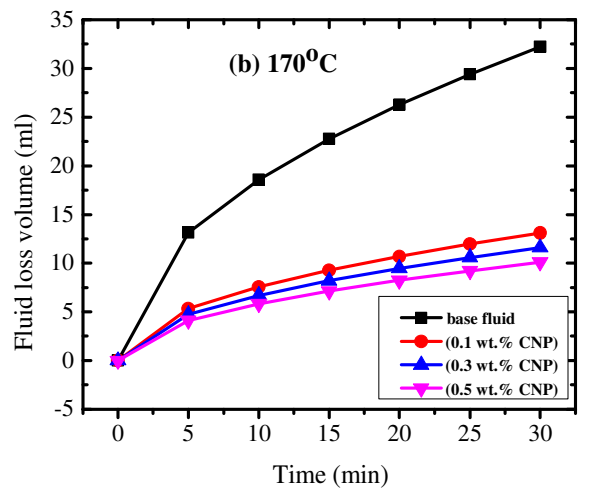

Figure 9: Fluid loss volume versus time of drilling mud 


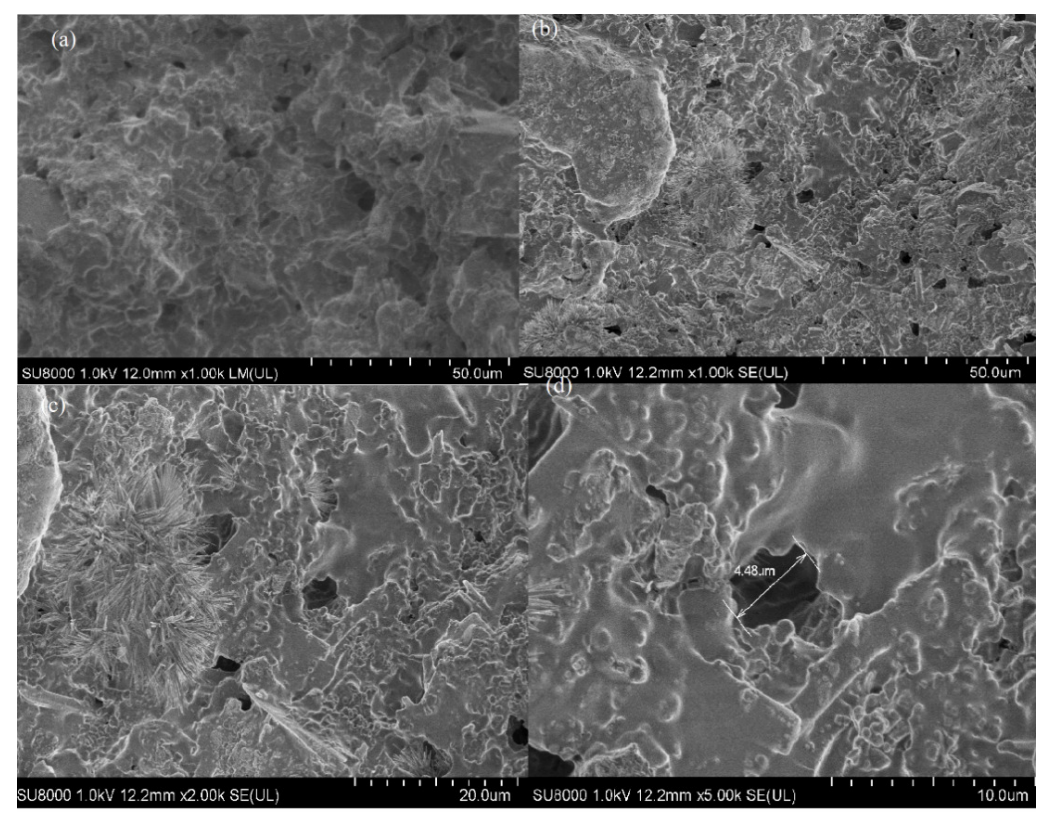

Figure 10: SEM micrographs of the filter cakes of the base fluid (a) and of CNP/PAC/BT-drilling mud ( $b, c$ and $d$ )

A good permeable filter cake will allow filtrates and fines to migrate into the porous formation, ultimately not damaging the formation. Figure 10 shows micrographs of the filter cakes of the base fluid (a) and of the CNP/PAC/BTdrilling mud ( $b, c$ and $d$ ). The addition of CNPs leads to the formation of a different microstructure, compared to that of the filter cake produced with the base fluid. The surface of the filter cake obtained with the CNPs appears to be very smooth, without significant anomalies, while the surface of the base fluid filter cake is substantially rougher.

The thickness of the filter cake of the $\mathrm{CNP} / \mathrm{PAC} / \mathrm{BT}$-silicate mud was measured to range from 0.06 to $0.16 \mathrm{~mm}$. The addition of CNPs might change the microstructure of the filter cakes, leading to changes in the permeability, ${ }^{19}$ and resulting in a reduction of filtration losses and in a thin filter cake. Furthermore, the improved viscosity of all the cellulose silicate-based muds reduced the rate of filtration and flocculation. The filter cakes of almost all the muds were good, except that of the base fluid at $170{ }^{\circ} \mathrm{C}$. The filter cakes were less thick due to a high amount of filtrate loss.

Generally, superior filtration performance comes along with the formation of a compact filter cake with low permeability. A relative decrease in the filter cake permeability was observed in Table 3 with the increase in CNPs concentration up to $0.5 \mathrm{wt} \%$ at different temperatures.

Table 3

Filter cake permeability of CNP-drilling muds

\begin{tabular}{cccc}
\hline $\begin{array}{c}\text { CNPs } \\
(\mathrm{wt} \%)\end{array}$ & $\begin{array}{c}\text { Filtrate rate } \\
q \times 10^{-3}\left(\mathrm{~cm}^{3} / \mathrm{s}\right)\end{array}$ & $\begin{array}{c}\text { Filter cake thickness } \\
(\mathrm{mm})\end{array}$ & $\begin{array}{c}\text { Permeability of filter cake } \\
\left(K \times 10^{-3} \mathrm{mD}\right)\end{array}$ \\
\hline & & At $150^{\circ} \mathrm{C}$ & \\
\hline 0.0 & 3.6 & 0.12 & 1.39 \\
0.1 & 1.6 & 0.09 & 0.46 \\
0.3 & 1.6 & 0.08 & 0.41 \\
0.5 & 1.5 & 0.06 & 0.29 \\
\hline & & At $170{ }^{\circ} \mathrm{C}$ & 8.43 \\
\hline 0.0 & 12.5 & 0.21 & 2.62 \\
0.1 & 5.1 & 0.16 & 1.88 \\
0.3 & 4.5 & 0.13 & 1.50 \\
0.5 & 3.9 & 0.12 & \\
\hline
\end{tabular}


These observations were completely consistent with the API fluid loss results, confirming that the filtration performance of the drilling fluids was substantially governed by the permeability of the deposited filter cakes. The effects of CNP addition to silicate-based drilling fluids were observed in comparison with the base fluid. It was observed that a small amount of CNPs can be used to achieve the required rheology and filtration properties at high temperature.

\section{CONCLUSION}

In this study, cellulose nanoparticles were extracted from corncob and then were used as an additive in silicate-based mud at different concentrations and temperatures. The presence of CNPs largely improved the rheological and filtration properties of the silicate mud. The experimental results showed that the addition of a small amount of CNPs (0.1-0.5 wt\%) to the silicate-based mud substantially increased the viscosity and yield stress, and reduced the filtration loss, filter cake permeability and filter cake thickness. Thus, the addition of CNPs was demonstrated to be promising for hightemperature drilling mud application, leading to various advantages, such as cutting transport capacity and reducing filtration loss. The Herschel-Bulkley model was found to be the best fitting model to the silicate-based drilling fluid containing CNPs. The study concludes that, using a small amount of CNPs (0.1 to $0.5 \mathrm{wt} \%$ ) increases the performance of silicate-based muds, and allows controlling their rheology and filtration loss at high temperature. In addition, applying this cheap, biodegradable, recyclable and environmentally friendly additive to drilling muds can reduce environmental pollution during disposal of the muds.

ACKNOWLEDGEMENT: The authors would like to acknowledge the National Natural Science Foundation of China (Contract No. 51904034) for the financial support. The authors also would like to thank Professors Mingbiao Xu and Weihong Liu for their assistance in this research.

\section{REFERENCES}

1 B. A. Hamad, M. Xu and W. Liu, Part. Sci. Technol.,

(2019),

https://doi.org/10.1080/02726351.2019.1675835 (in press)

2 A. Aftab, A. R. Ismail, Z. H. Ibupoto, H. Akeiber and M. G. K. Malghani, Renew. Sustain. Energ. Rev., 76, $1301 \quad$ (2017), http://dx.doi.org/10.1016/j.rser.2017.03.050

F. Alakbari, S. Elkatatny, M. S. Kamal and M. Mahmoud, in Procs. SPE 192191-MS Conference, Kingdom of Saudi Arabia, April 23-26, 2018, http://doi.org/10.2118/192191-MS

4 T. Soric, P. Marinescu and R. Huelke, in Procs. IADC/SPE Drilling Conference, U.S.A, March 2-3, 2004, http://doi.org/10.2118/87133-MS

5 M. Mcdonald, in Procs. SPE 162180 Conference, Alberta, Canada, 30 October - 1 November, 2012, pp. 1-9, https://doi.org/10.2118/162180-MS

6 J. Duncan and M. Mcdonald, in Procs. SPE 86700 Conference, Alberta, Canada, March 29-31, 2004, https://doi.org/10.2118/86700-MS

7 S. Alford, A. Dzialowski, P. Jiang and H. Ullmann, in Procs. SPE/IADC 67737 Conference, The Nertherlands, 27 February-1 March, 2001, https://doi.org/10.2118/67737-MS

8 E. V. Oort, D. Ripley, I. Ward, J. W. Chapman, R. Williamson et al., in Procs. SPE/IADC 35059 Drilling Conference, Louisiana, March 12-15, 1996, http://doi.org/10.2118/35059-MS

9 V. C. Kelessidis, Rheology, 1, 1 (2017), http://omicsonline.org/open-acess/yield-stress-ofbentonite-dispersions.php?aid $=84232$

10 M. Amanullah and L. Yu, J. Petrol Sci. Eng., 48, 199 (2005), http://doi.org/10.1016/j.petrol.2005.06.013

11 S. Agarwal, P. Tran, Y. Soong, D. Martello and R. K. Gupta, in Procs. AADE-11-NTCE-3 Conference, Texas, April 12-14, 2011, pp. 1-6, http://www.pdf.semanticscholar.org/c9fe/e73d0dcba27 2e1b2756792cf1ba15a91e789.pdf

12 M. Zakaria, M. M. Husein and G. Harland, in Procs. SPE 156992 Conference, The Nertherlands, June 12-14, 2012, http://doi.org/10.2118/156992-MS

13 Z. Vryzas, O. Mahmoud, H. A. Nasr-El-Din and V. C. Kelessidis, in Procs. IPTC-18381-MS Conference, Qatar, December 6-9, 2015, https://doi.org/10.2523/IPTC-18381-MS

14 J. Behari, Indian J. Exp. Biol., 48, 1008 (2010), http://www.nopr.niscair.res.in/bitstream/123456789/10 346/1/1JEB\%2048(10)\%201008-1019.pdf

15 M. Li, Q. Wu, K. Song, Y. Qing and Y. Wu, ACS Appl. Mater. Interfaces, 7, 5006 (2015), http://doi.org/10.1021/acsami.5b00498

16 F. T. G. Dias, R. R. Souza and E. F. Lucas, Fuel, 140 , 711 (2015), http://dx.doi.org/10.1016/j.fuel.2014.09.074

17 R. W. Anderson and R. B. James, in Procs. SPE 5005 Conference, Texas, October 6-9, 1974, pp. 1-5, http://doi.org10.2118/5005-MS

18 R. C. Navarrete, R. E. Himes and J. M. Seheult, in Procs. SPE 59535 Conference, U.S.A., March 21-23, 2000, http://doi.org/10.2118/59535-MS 
19 B. Warren, P. Van der Horst and W. Stewart, in Procs. SPE 80210 Conference, U.S.A., February 5-7, 2003, http://doi.org/10.2118/80210-MS

20 C. Liu, B. Hong, K. Xu, M. Zhang, H. An et al., Polym. Bull., 71, $3051 \quad$ (2014), http://doi.org/10.1007/s00289-014-1237-8

21 R. Rafati, S. R. Smith, A. S. Haddad, R. Novara and H. Hamidi, J. Petrol Sci. Eng., 161, 61 (2017), http://doi.org/10.1016/j.petrol.2017.11.067

22 D. V. Kosynkin, G. Ceriotti, K. C. Wilson, J. R. Lomeda, J. T. Scorsone et al., ACS Appl. Mater. Interfaces, $\quad \mathbf{4} \quad 222 \quad$ (2012), https://pubs.acs.org/doi/10.1021/am2012799

23 A. R. Ismail, A. Aftab, Z. H. Ibupoto and N. Zolkifile, J. Petrol Sci. Eng., 139, 264 (2016), https://doi.org/10.1016/j.petrol.2016.01.036

24 E. Fortunati, D. Puglia, M. Monti, C. Santulli, M. Maniruzzaman et al., Appl. Polym., 128, 3220 (2012), http://doi.org/10.1002/app.38524

25 S. Huang, L. Zhou, M.-C. Li, Q. Wu and D. Zhou, Materials, $\quad \mathbf{1 0}, \quad 80 \quad$ (2017), http://doi.org/10.3390/ma10010080

26 Y. Jung, M. Barry, J.-K. Lee, P. Tran, Y. Soong et al., in Procs. AADE-11-NTCE-2 Conference, Texas, April 12-14, 2011, pp. 1-4, http://doi.org/AADE-11NTCE-2

27 Z. Vryzas, V. Zaspalis and L. Nalbantian, in Procs. IPTC-18731-MS Conference, Thailand, November 1416 , 2017 , http://doi.org/10.1017/CBO9781107415324.004

28 M.-C. Li, Q. Wu, K. Song, C. F. De Hoop, S. Lee et al., Ind. Eng. Chem. Res., 55, 133 (2016), https://pubs.acs.org/doi/10.1021/acs.iecr.5b03510

29 O. Mahmoud, H. A. Nasr-El-Din, Z. Vryzas and V. C. Kelessidis, in Procs. SPE 178949-MS Conference, U.S.A., February 24-26, 2016, http://doi.org/10.2118/178949-MS

30 M. M. Barry, Y. Jung, Y. J.-K. Lee, T. X Phuoc and M. K. Chyu, J. Petrol Sci. Eng., 127, 338 (2015), http://dx.doi.org/10.1016/j.petrol.2015.01.012

31 M. Amani and M. Al-Jubouri, Energ. Sci. Technol., 4, 27 (2012), http://doi.org/10.3968/j.est.1923847920120401.256ISS $\mathrm{N}$

32 API Specification 13B-1, Recomm. Pract. for Field Test Water-Based Drill. Fluids, (2003), http://www.ballots.api.org.ecs/sc13/API_RP13B-

5Ed_TestingWBDF_4316.pdf

33 I. K. Chinwuba, O. N. Princewill and O. C. Vivian, Int. J. Appl. Innov. Eng. Manag., 5, 259 (2016), http://www.ijaiem.org/Volume5Issue5/IJAIEM-201509-22-20.pdf

34 E. C. Bingham, Bull. Bur. Stand., 13, 309 (1916), https://doi.org/10.1007/BF01432034

35 H. Ziaee, M. Arabloo, M. H. Ghazanfari and D. Rashtchian, Chem. Eng. Res. Des., 93, 21 (2015), https://dx.doi.org/10.1016/j.cherd.2014.03.023

36 W. H. Herschel and R. Bulkley, Colloid Polym. Sci., 39, 291 (1926), https://doi.org/10.1007/BF01432034
37 H. Pan, Appl. Polym. Sci., 105, 3740 (2007), http://doi.org/ 10.1002/app.26435

38 R. Wongsagonsup, S. Shobsngob, B. Oonkhanond and S. Varavinit, Starch, 57, 32 (2005), http://doi.org/10.1002/star.200400311

39 C. J. Rueb and C. F. Zukoski, J. Rheol., 42, 1451 (1998), http://doi.org/10.1122/1.550966

40 R. L. Hoffman, J. Coll. Interf. Sci., 46, 491 (1974), http://doi.org/10.1016/0021-9797(74)90059-9

${ }^{41}$ L. B. Chen, M. K. Chow, B. J. Ackerson and C. F. Zukoski, Langmuir, 10, $2817 \quad$ (1994), http://doi.org/10.1021/la00020a052

${ }^{42}$ K. Benhamou, A. Dufresne, A. Magnin, G. Mortha and H. Kaddami, Carbohyd. Polym., 99, 74 (2014), http://doi.org/10.1016/j.carbpol.2013.08.032

43 C. N. Wu, T. Saito, S. Fujisawa, H. Fukuzumi and A. Isogai, Biomacromolecules, 13, 1927 (2012), http://doi.org/ 10.1021/bm300465d

44 F. A. Makinde, A. D. Adejumo, C. T. Ako and V. E. Efeovbokhan, Pet. Coal, 53, 167 (2011), http://www.vurup.sk/petroleum-coal

45 M. Amanullah, K. Al-Arfaj and Z. Al-Abdullatif, in Procs. SPE/IADC 139534 Conference, The Nertherlands, March 1-3, 2011, http://doi.org/10.2118/139534-ms

46 J. Mewis, W. J. Frith, T. A. Strivens and W. B Russel, AIChE J., 35, $415 \quad$ (1989), http://doi.wiley.com/10.1002/aic.690350309

47 D. R. Tobergte and S. Curtis, Clim. Change, 53, 1 (2013), http://doi.org/10.1017/CBO9781107415324.004

${ }_{48}$ S. P. Makonjwa, PhD Thesis, University of the Witwatersrand, http://www.hdl.handle.net/10539/18381

(2015),

49 J. Karen, M. William, S. Ponmani, R. Samuel, R. Nagarajan et al., J. Petrol Sci. Eng., 117, 15 (2014), http://dx.doi.org/10.1016/j.petrol.2014.03.005

50 S. Ponmani, R. Nagarajan and J. Sangwai, SPE J., 21, $405 \quad$ (2016), http://dx.doi.org/10.1016/j.petrol.2014.03.005

51 C. O. Chike-Onyegbula, J. Brew. Distill., 3, 6 (2012), http://doi.org/ 10.5897/JBD11.018

52 A. Chami Khazraji and S. Robert, J. Nanomater., 2013, 10 (2013), http://doi.org/10.1155/2013/409676 